\title{
THE INFLUENCE OF THE ENDOCRINE SYSTEM ON INTRAOCULAR TENSION
}

\author{
JOSEPH IMRE, JR., M.D. \\ Professor of Ophthalmology, Elisabeth State University \\ BUDAPEST, HUNGARY
}

This report comprises a short summary of my clinical observations as regards the relation between intraocular tension and the internal secretions. The way such a relationship was suggested has been already published $(1,2)$. This report is presented in the hope that it will lead others to extend the observations in cases of different dysfunctions of the various endocrine glands.

The current theories which seek to explain the regulation of intraocular tension are more or less inadequate to account for our clinical experiences. Even those based on blood pressure are unsatisfactory, because we find that: (1) the tension of normal eyes can change without change of the blood pressure; (2) there are cases in which the eyes of young individuals with relatively high blood pressure show a lasting hypotension; (3) we find sometimes in case of normal eyes a remarkably high tension, although the blood pressure is normal or even lower than the average for the given age.

These facts interested me particularly because I have made systematic studies with the tonometer of Schiötz since 1910 (3) and was led to the conclusion that the long discussed problem of glaucoma will not be solved either by anatomical studies alone or by studies of the blood pressure and changes in the intraocular blood vessels. We have reason to believe that acute inflammatory glaucoma as well as so-called simple glaucoma is only a manifestation of certain constitutional abnormalities. I should like to go a step further and say that even those anatomical anomalies predisposing to glaucoma could be looked upon as probable consequences of certain constitutional anomalies. This conclusion is suggested by knowledge of certain families, several members of which have an unusually great degree of hypermetropia, small eyeballs with relatively large lenses, etc. 
Three years ago quite an unusual case was observed in my eye clinic in Pozsony, Pressburg, ${ }^{*}$ which afforded a hint to go farther in studies along this line. The patient was a pregnant woman who showed signs of osteomalacia. Her eyeballs lost their original form, the cornea of both eyes was wrinkled and the eyeballs were so soft that the simple cohesion between the conjunctiva tarsi and bulbi was enough to lead to a deep wrinkle on the upper part of the sclera when the lower lid was pulled down.

The normal intraocular tension is between 15 and $26 \mathrm{~mm}$. $\mathrm{Hg}$ pressure and when the heart stops beating it sinks to $8 \mathrm{~mm}$. $\mathrm{Hg}$. In this case the intraocular tension was less than that of a cadaver, it being even less than $5 \mathrm{~mm}$. $\mathrm{Hg}$. I searched for the explanation and what first set me to thinking was a coincidence of pregnancy and osteomalacia. I reflected that either of these conditions may lead to some degree of subtension and the two together all the more.

This conception led to a systematic examination of the eye tension of pregnant women. We found that among 50 subjects there were 42 with decidedly subnormal tension, two with normal and six with high tension. Those who had hypotension of the eyes showed the signs of pregnancy in the face, hands, skin, etc. These signs are regarded as due principally to hyperpituitarism, which is more or less pronounced in case of pregnancy (Erdheim and Stumme). The average tension of the 42 pregnant women was $12 \mathrm{~mm}$. $\mathrm{Hg}$, i. e., much less than the average normal eye tension, which is $20 \mathrm{~mm}$. Hg.

Those who had hypertension-and one had even $31 \mathrm{~mm}$. Hg pressure, although the eyes were clinically normal-looked unusually fresh in spite of their pregnancy and the facial signs of pregnancy in the lines and color were totally absent. It may be supposed that in these cases the ordinary hyperfunction of the hypophysis was not present.

In the meantime, we had opportunity to examine a patient who had atrophy of the optic nerves, bitemporal hemianopsia, cessation of menstruation and enlarged sella turcica, as shown by radioscopy. The intraocular tension in this case was $11 \mathrm{~mm} . \mathrm{Hg}$

*The Elisabeth State University originally was located there; in the summer of 1919 the Chech government compelled us to Ieave it. Since then the work is carried on in Budapest. 
in the right eye and $12 \mathrm{~mm}$. in the left. A second and a third case of hypophysis tumor showed similar hypotension.

One patient showed typical signs of acromegaly, but for a considerable time had been under $x$-ray treatment and for several months had received thyroid tablets; the pathological process had been arrested as shown by the fact that for two years the measurements of the bones, extremities, etc., had not changed. In this case visual acuity as well as the field of vision was the same as two years before; the tension was perfectly normal. This spoke for the fact that the balance of the endocrine system had been restored. This observation offers hope that we shall be able to use these ocular tension examinations to decide whether in certain cases treatment has had a satisfactory effect.

This supposition seems to be strengthened by a few cases of osteomalacia. Two cases which were not treated before the examination of the tension took place, had very decidedly low eye tension (the one 12 and $13 \mathrm{~mm}$. $\mathrm{Hg}$, the other less than $5 \mathrm{~mm}$.). Of the three patients which were operated upon (castration) before we examined their tension, one failed to show any conspicuous improvement of the clinical symptoms; she could not stand on her feet and had as much pain as before the operation. This patient had subtension (12 mm.) in both eyes. The other two, who got decidedly better, had normal tension. The only remarkable circumstance was the great difference of the tension between the right and left eyes. The rule is that both normal eyes in any given subject have the same tension. The tension in one of these cases was $23 \mathrm{~mm}$. $\mathrm{Hg}$ in the right and $15 \mathrm{~mm}$. in the left eye; in the other case it was $18 \mathrm{~mm}$. in the right and $15 \mathrm{~mm}$. in the left eye.

The only previous publication which gave a hint that abnormal eye tension may be connected with dysfunction of certain endocrine glands was that of Hippel (4), who found that patients with glaucoma gave a positive Abderhalden reaction with thyroid and thymus. Although these findings did not induce many investigators to extend the studies, they deserve the greatest attention.

Later on, Hertel (5) found that patients with hyperfunction of the thyroid have low intraocular tension and patients with glancoma have signs of hypofunction of the thyroid. Wessely 
(6) affirmed that the eye tension of patients with Graves' disease is in most cases lower than normal.

My experience does not confirm this. I have found among patients with Graves' disease more who had high tension than low tension; several with decidedly low tension were seen, however. In the older literature we find several articles with the statement that in Graves' disease the high tension of the eye is not a rare exception. Brailey and Eyre (7) several times found deep excavation and high intraocular tension in such cases. They, however, did not use a tonometer, but judged by touch only. Gail (8), too, in one case of Graves' disease, found high tension and deep excavation of the optic nerve. In Hippel's article we find a case of Graves' disease ("forme fruste") connected with glaucoma simplex.

It would seem unsafe, therefore, to accept as generally true the statement regarding the low tension in Graves' disease. This apparent contradiction in the results of our examinations is easy to understand if we consider the great variability of the symptoms of this illness. In my experience Graves' disease can cause either type of abnormal eye tension. But in either case we find almost regularly a remarkable difference of tension between the right and the left eyes, and a pronounced lability of the tension even during the measurement. This proves that the regulation of the tension is disturbed.

\section{SUMMARY}

We find that a disturbance in the balance of the endocrine system causes a disturbance in the intraocular tension. When the balance is restored the intraocular tension approaches or becomes normal. Therefore we may conclude that the hitherto unsettled question of the regulation of the intraocular tension depends primarily on the function of the endocrine glands. Although the disturbed function of one gland of this system provokes a change in the function of others and, therefore, we usually have to do with a pluriglandular disturbance, the glands that seem to play the principal role in the regulation are the hypophysis, thyroid, thymus and gonads.

Determining of the lasting changes in the intraocular tension may give us important hints and may be used as a valuable diagnostic help when we suspect some disturbance of the endo- 
crine system or in the function of one certain gland. We recommend, therefore, the careful and systematic measuring of the eye tension with the tonometer as a diagnostic and in some cases prognostic auxiliary method.

Further observations and therapeutic findings, which are purely of ophthalmological interest, will be published in special ophthalmological journals.

\section{HIHLIOGRAPHY}

1. Imre, J., Jr.: The question of the regulation of intraocular tension. Orvosi Hetilap. 1920, (Hungarian).

2. Die regulatorische Wirkung der endokrinen Drüsen auf den intraocularen Druck. Arch. f. Augenheilk., 1921, 88, 155-167.

3. Experiences with the tonometer of Schiötz. Szemészet, 1911. (Hungarian).

4. Hippel.: Graefe's Arch. f. Ophthalmol., Festschrift f. Sattler, 1915, 90, 19 .

5. Hertel: Weiterer Beitrag zur Lehre von Augendruck. Bericht der Ophthalmol. Gesellschaft Heidelberg, 1919.

6. Wessely: Comments on Hertel's paper. Ibid.

7. Gall: Die Basedow'ssche Krankheit. Inaug. Dissertation, München, 18\$3; Quoted by Sattler, Graefe-Saemisch.

8. Bralley \& Eyre: Exophthalmic golter, associated with increased intraocular tension. Guy's Hosp. Reports, vol. liv, and Ophthalmic Review, 20, 147; Quoted by Sattler, Graefe-Saemisch, ix, ii. iv. Kecskeméti-u. 14. Budapest, Hungary. 